\title{
An Evaluation of Peak Expiratory Flow Monitoring: A Comparison of Sitting Versus Standing Measurements
}

\author{
Emily K. McCoy, PharmD, Jeremy L. Thomas, PharmD, Rebecca S. Sowell, PharmD, \\ Christa George, PharmD, Christopher K. Finch, PharmD, Elizabeth A. Tolley, PhD, \\ and Timothy H. Self, PharmD
}

Introduction: Current guidelines for the diagnosis and management of asthma suggest that patients perform peak expiratory flow (PEF) measurements while standing; however, recent literature suggests this may not be necessary. The purpose of this study was to determine the impact of patient position on PEF measurements.

Methods: A randomized observational analysis of PEF measurements for 211 patients in sitting and standing positions was performed. The highest PEF measurement from tests performed with correct technique in both the sitting and standing position was compared.

Results: Overall, PEF measurements did not significantly differ between the sitting and standing positions $(506 \pm 2 \mathrm{~L} / \mathrm{min}$ versus $508 \pm 2 \mathrm{~L} / \mathrm{min} ; P=.45)$. No differences were seen between mean PEF measurements in the sitting or standing positions for either women or men, nor were there significant differences between mean PEF values for the sitting and standing positions in participants who reported a history of asthma.

Conclusions: PEF measurements do not significantly differ based on sitting or standing measurements among healthy participants. Based on the results of this study it may not be necessary for the patient to stand while performing PEF measurements. Further study among patients with asthma is warranted. (J Am Board Fam Med 2010;23:166-170.)

Keywords: Peak Expiratory Flow, Sitting, Standing, Reliability

Asthma is a chronic inflammatory disease of the airways that affects more than 22 million Americans, including almost 7 million children. ${ }^{1,2} \mathrm{Un}-$ controlled asthma can cause significant burden to patients, including decreased quality of life, lost

This article was externally peer reviewed.

Submitted 18 May 2009; revised 21 August 2009; accepted 24 August 2009.

From the Department of Pharmacy Practice, Auburn University Harrison School of Pharmacy (EKM); Department of Pharmacy Practice, College of Pharmacy, University of Arkansas for Medical Sciences, Little Rock (JLT); Methodist University Hospital (RSS, CKF, THS); University of Tennessee-St. Francis Family Practice (CG); and Department of Clinical Pharmacy, College of Pharmacy (CG, CKF, THS) and Departments of Preventative Medicine and Medicine (Pulmonary and Critical Care Medicine), College of Medicine (EAT), University of Tennessee Health Science Center (CG, CKF, EAT, THS), Memphis.

Funding: none.

Conflict of interest: none declared.

Corresponding author: Emily K. McCoy, PharmD, Department of Pharmacy Practice, Auburn University Harrison School of Pharmacy, Research Park Building 3, Suite 2100, 307 University Boulevard North, Mobile, AL 36688 (E-mail: ekm0010@auburn.edu). days of school or work, hospitalizations, and death. When patients are diagnosed with asthma, it is important to educate them about proper asthma management, including, but not limited to, medication use and adverse effects, inhalation technique, and signs and symptoms of asthma exacerbations.

Appropriate asthma management relies heavily on the patient's ability to regularly self-monitor asthma symptoms. Even well-controlled patients need to be monitored over time to reassess asthma severity and adjust medications as needed. Selfmonitoring involves not only the assessment of the frequency and severity of symptoms but also the measurement of pulmonary function, which is often done by measuring the peak expiratory flow (PEF). Daily PEF monitoring can be helpful to detect changes in disease states that require treatment, evaluate response to changes in therapy, and can provide a quantitative measurement of impairment. ${ }^{3}$ The current National Asthma Education and Prevention Program Expert Panel Report 3 
guidelines suggest that, in addition to symptomatic monitoring in asthmatic patients, pulmonary function should also be assessed periodically. ${ }^{3}$ The Expert Panel suggested that long-term, daily PEF monitoring should be considered for patients who have moderate or severe persistent asthma, who have a history of severe exacerbations, who poorly perceive airflow obstruction and worsening asthma, and for those patients who prefer that method of monitoring. ${ }^{3}$ Monitoring PEF can assist in determining the severity of the patient's asthma and can guide therapeutic decisions in the home, the school, the clinician's office, or the emergency department.

PEF measurements are also useful in the development of a written Asthma Action Plan, which should be given to every patient with asthma. The Asthma Action Plan should include instructions for both daily management and management of exacerbations (Figure 1). It is important to note that the 3 zones in the Asthma Action Plan are determined by the patient's personal best PEF measurement.

Current guidelines suggest that patients be standing as they use their peak flow meter; however, patients may be unable to stand for numerous reasons. Therefore, the purpose of this study is to evaluate what, if any, differences exist between PEF measurements taken in the standing and sitting positions.

\section{Methods}

\section{Study Design and Participants}

This was a prospective, randomized study in which participants were recruited from the University of Tennessee Health Science Center in Memphis, Tennessee. The study was approved by the Institutional Review Board of the University of Tennessee.

Men and women of all ethnic groups who were at least 18 years of age and were enrolled in the Basic Clinical and Communication Skills course at the University of Tennessee College of Pharmacy were eligible to participate in this study. The participants had received a lecture and demonstrations regarding correct and incorrect PEF technique before enrolling in the study. Participants who reported a history of asthma and smokers were also included. Participants were excluded if they were not enrolled in the Basic Clinical and Communication Skills course or were younger than 18 years of age.

\section{Procedures}

Data collected included age, gender, height, the presence or absence of obstructive airway disease or other pulmonary diseases, current smoking status, and any medications that may affect pulmonary function. If the participant was taking medications that could affect pulmonary function, he or she was asked to list the name of the medication, dose, and the time of the last dose taken. To ensure privacy of each individual, the data collection forms were assigned a study number rather than a personal identifier.

Participants were randomized to perform the PEF maneuver in either the sitting or standing position first; however, they performed the PEF maneuver in both positions. Participants were divided into groups of 8 to 12 and an investigator was assigned to each group. Using a TruZone ${ }^{\circledR}$ peak flow meter (Monaghan Medical Corp., Plattsburg, NY), the respective investigator demonstrated the proper use of the peak flow meter in the standing position (as directed in the current National Asthma Education and Prevention Program guidelines; Figure 2). ${ }^{3}$ For the sitting position, participants were instructed to sit with their backs straight in a chair with knees bent and feet flat on the floor rather than standing with legs shoulder width apart. Participants were then allowed to practice using the peak flow meters until they were comfortable with the technique. Once the participants received adequate instruction and time to practice, investigators directly observed each participant perform 3 PEF measurements in either the sitting or standing position first, as was dictated by the data collection form. Investigators also observed whether the measurement was conducted with proper technique. The participant was allowed to rest briefly and then he or she performed 3 more measurements in the alternate position. Therefore, each subject performed 6 PEF measurements. All measurements were recorded. Consistent with recommended procedures in patient care, only the highest measurements for both the sitting and standing positions were analyzed.

\section{Statistical Analysis}

For demographic variables, means, standard deviations, and frequencies were computed. The primary variable of interest was $\mathrm{PEF}(\mathrm{L} / \mathrm{min})$ obtained in the sitting and standing positions. These results 
Figure 1. Sample Asthma Action Plan. (Reprinted with permission from Regional Asthma Management and Prevention [RAMP], a program of the Public Health Institute. The RAMP Asthma Action Plan was supported by Cooperative Agreement Number 1U58DP001016-01 from the Centers for Disease Control and Prevention. The contents of the RAMP Asthma Action Plan are solely the responsibility of the authors and do not necessarily represent the official views of the CDC. ${ }^{4}$ )

\section{My Asthma Plan english Patient Name:}

\section{Medical Record \#:}

Provider's Name: DOB

Provider's Phone \#: Completed by:

Date:

\begin{tabular}{|c|c|c|c|}
\hline Controller Medicines & How Much to Take & How Often & Other Instructions \\
\hline & & $\begin{array}{l}\text { times per day } \\
\text { EVERY DAY! }\end{array}$ & Gargle or rinse mouth after use \\
\hline & & $\begin{array}{l}\text { times per day } \\
\text { EVERY DAY! }\end{array}$ & \\
\hline & & $\begin{array}{l}\text { times per day } \\
\text { EVERY DAY! }\end{array}$ & \\
\hline & & $\begin{array}{l}\text { times per day } \\
\text { EVERY DAY! }\end{array}$ & \\
\hline Quick-Relief Medicines & How Much to Take & How Often & Other Instructions \\
\hline $\begin{array}{l}\square \text { Albuterol (ProAir, Ventolin, Proventil) } \\
\square \text { Levalbuterol (Xopenex) }\end{array}$ & $\begin{array}{l}\square 2 \text { puffs } \\
\square 4 \text { puffs } \\
\square 1 \text { nebulizer treatment }\end{array}$ & $\begin{array}{l}\text { Take ONLY as needed } \\
\text { (see below - starting in } \\
\text { Yellow Zone or before } \\
\text { excercise) }\end{array}$ & $\begin{array}{l}\text { NOTE: If you need this medicine more } \\
\text { than two days a week, call physician to } \\
\text { consider increasing controller medica- } \\
\text { tions and discuss your treatment plan. }\end{array}$ \\
\hline
\end{tabular}

Special instructions when I am

doing well,

getting worse,

having a medical alert.

Doing well.

- No cough, wheeze, chest tightness, or shortness of breath during the day or night.

- Can do usual activities.

Peak Flow (for ages 5 and up):

is __ or more. ( $80 \%$ or more of personal best)

Personal Best Peak Flow (for ages 5 and up):

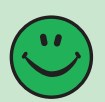

PREVENT asthma symptoms every day:

$\square$ Take my controller medicines (above) every day.

$\square$ Before exercise, take ___ puff(s) of

$\square$ Avoid things that make my asthma worse. (See back of form.)

CAUTION. Continue taking every day controller medicines, AND:

\section{Getting worse.}

- Cough, wheeze, chest tightness, shortness of breath, or

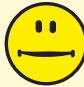

Waking at night due to asthma symptoms, or

- Can do some, but not all, usual activities.

Peak Flow (for ages 5 and up):

$$
\text { to ___ (50 to } 79 \% \text { of personal best) }
$$

\section{Medical Alert}

- Very short of breath, or

- Quick-relief medicines have not helped, or

- Cannot do usual activities, or

- Symptoms are same or get worse after 24 hours

in Yellow Zone.

Peak Flow (for ages 5 and up):

less than ( $50 \%$ of personal best)

If I am not back in the Green Zone within 20-30 minutes take

Increase

Continue using quick relief medicine every 4 hours as needed. Call provider if not improving in ___ days.

\section{MEDICAL ALERT! Get help!}

Take quick relief medicine: ___ puffs every ___ minutes

$\square$ Take

$\square$ Call

Danger! Get help immediately! Call 911 if trouble walking or talking due to shortness of breath or if lips or fingernails are gray or blue. For child, call 911 if skin is sucked in around neck and ribs during breaths or child doesn't respond normally.

Health Care Provider: My signature provides authorization for the above written orders. I understand that all procedures will be implemented in accordance with state laws and regulations. Student may self carry asthma medications: $\square$ Yes $\square$ No self administer asthma medications: $\square$ Yes $\square$ No (This authorization is for a maximum of one year from signature date.) 
Figure 2. Directions for peak flow meter use. (Adapted from National Heart, Blood, and Lung Institute Expert Panel. Report 3: guidelines for the diagnosis and management of asthma. Bethesda, MD: National Institutes of Health; 2007.3)

- Six steps for using a PFM

1. Move the indicator to the bottom of the numbered scale.

2. Stand up.

3. Hold without obstructing mouthpiece

4. Take a deep breath, completely filling lungs.

5. Place the mouthpiece in your mouth and close lips around it, forming a tight seal so that no air will leak out.

6. Breathe out as hard and as fast as you can- Blast!

were analyzed using the repeated measures analysis of variance, with subject included as a random (block) variable and position as a fixed effect. Additional analyses were conducted using a nested factorial design with the following effects in the model: sex (fixed effect), subject nested within sex (random), position (fixed effect), and the interaction of sex and position (fixed effect). All contrasts were preplanned and made with $\alpha=0.05$. SAS software for Windows (SAS Institute, Cary, NC) was used for all statistical analysis.

\section{Results}

A total of 211 healthy men and women, ranging from 20 to 43 years of age, completed the study (Table 1). Twenty-nine (13.7\%) participants reported a history of asthma. Of those who had a history of asthma, 19 reported currently using medications to treat asthma symptoms. Ten particiapants $(4.7 \%)$ reported smoking, with 4 of these being current smokers and 6 being previous smokers who had quit at least 3 months before the study began.

Overall, the means for PEF were not significantly different when obtained from the sitting position versus the standing position $(506 \pm 2$

Table 1. Demographics

\begin{tabular}{lccc}
\hline & $\begin{array}{c}\text { Patients } \\
(\mathrm{n}[\%])\end{array}$ & $\begin{array}{c}\text { Age } \\
(\text { mean years } \pm \text { SD) }\end{array}$ & $\begin{array}{c}\text { Height } \\
(\text { mean inches } \pm \text { SD) }\end{array}$ \\
\hline Men & $63(30)$ & $23.6 \pm 2.0^{*}$ & $71.7 \pm 2.4$ \\
Women & $148(70)$ & $23.5 \pm 2.7$ & $65.1 \pm 2.7^{\dagger}$ \\
Total & 211 & $23.5 \pm 2.5$ & $67.0 \pm 4.0$ \\
\hline
\end{tabular}

*Two male subjects were excluded from age analysis because of no reported age.

${ }^{\dagger}$ One female subject was excluded from height analysis because of no reported height.
$\mathrm{L} / \mathrm{min}$ vs $508 \pm 2 \mathrm{~L} / \mathrm{min} ; P=.45)$. No differences were seen between mean PEF measurements from the sitting and standing positions among either women or men (Table 2). There was also no significant difference between mean PEF values for the sitting and standing positions among participants who reported a history of asthma or in those who reported a history of smoking (Table 2). Consistent with predicted values, there were significant differences detected when comparing the PEF measurements of men to those of women in both sitting and standing positions $(P<.0001)$.

\section{Discussion}

In this study we assessed the impact of body position on PEF measurements in both the sitting and standing positions. Overall there was no significant difference in mean PEF seen in the standing versus sitting positions, nor were there significant differences seen in subgroup analysis. Although the asthmatic population did have higher average PEF measurements than women, this is most likely because the asthma subgroup included both men and women.

The current National Asthma Education and Prevention Program guidelines include patient instructions for using a peak flow meter that require

Table 2. Peak Expiratory Flow Measurements (L/min)*

\begin{tabular}{llll}
\hline & Sitting & Standing & $P$ \\
\hline $\operatorname{Men}^{\dagger}(\mathrm{n}=63)$ & $672 \pm 9^{\dagger}$ & $684 \pm 9^{\dagger}$ & .12 \\
Women $^{\dagger}(\mathrm{n}=148)$ & $440 \pm 5^{\dagger}$ & $443 \pm 5^{\dagger}$ & .90 \\
Asthmatics $(\mathrm{n}=29)$ & $504 \pm 5$ & $509 \pm 5$ & .39 \\
Smokers $(\mathrm{n}=10)$ & $551 \pm 6$ & $539 \pm 6$ & .21 \\
\hline
\end{tabular}

*Values provided as mean \pm standard error of the mean. ${ }^{\dagger} P<.0001$. 
patients to stand while using the peak flow meter. ${ }^{3}$ However, spirometry testing, which is used in the initial diagnosis of asthma and other pulmonary diseases, may be performed either sitting or standing, but the position must be recorded. ${ }^{5,6}$

The literature examining the impact of patient position on PEF measurements is limited. Vaswani and colleagues ${ }^{7}$ evaluated peak flow measurements in both the standing and sitting positions for 33 healthy men and women aged 18 to 58 years. $\mathrm{Pa}-$ tients were excluded if they had asthma or any other respiratory problems, if they were taking any medication (particularly bronchodilators), and if they smoked. ${ }^{7}$ The authors found no significant differences between the standing and sitting peak flow measurements, nor were any differences seen when the patients used a nose clip. ${ }^{7}$

A similar study performed in Japan by Nagasaka et $\mathrm{al}^{8}$ included a total of 74 patients, 32 of which reported a history of asthma. The authors found no differences between standing and sitting peak flow measurements and that peak expiratory flow did not differ when a nose clip was used in either the healthy population or the patients who reported a history of asthma. ${ }^{8}$ However, healthy patients did have higher average PEF measurements than did those with asthma. ${ }^{8}$ A third study examined the impact of gestational age and maternal position in sitting, standing, and supine positions on the rate of decline of PEF measurements. This study included 38 healthy, pregnant women with a mean age of 31.2 years. The authors found that, although gestational age had a significant impact on PEF measurements, no significant differences were seen between the measurements taken in the sitting and standing positions. ${ }^{9}$

Each of these studies was conducted with a small number of relatively healthy patients; this can limit the applicability of these studies to larger, asthmatic populations. In contrast, our current study was conducted among a larger population. However, there are some limitations to this study. Our participants were mainly young, healthy students at the health science center but we recognize the need for further study among patients with asthma who have a range of ages. There were also a small number of asthmatics included, but not every participant who reported a history of asthma was taking medications for asthma. Because asthma medications, particularly bronchodilators, can affect $\mathrm{PEF}$, it would be extremely useful to determine the impact of testing PEF results by position among a larger group of asthmatics. Further studies are needed in a strictly asthmatic population to determine what, if any, differences exist in PEF measurements.

\section{Conclusion}

Based on the results of this study, it may be unnecessary to stand while performing PEF measurements. Larger studies involving the previously mentioned populations, particularly a larger asthmatic population, are needed to further evaluate the impact of patient position on PEF measurements.

\section{References}

1. US Department of Health and Human Services, Centers for Disease Control and Prevention, National Center for Health Statistics. Summary health statistics for US adults: National Health Interview Survey 2006. Available from http://www.cdc. gov/nchs/data/series/sr_10/sr10_235.pdf. Accessed 2 January 2010.

2. US Department of Health and Human Services, Centers for Disease Control and Prevention, National Center for Health Statistics. Summary health statistics for US children: National Health Interview Survey 2006. Available from http://www.cdc.gov/ nchs/data/series/sr_10/sr10_234.pdf. Accessed 2 January 2010.

3. National Asthma Education and Prevention Program Expert Panel. Expert panel report 3: guidelines for the diagnosis and management of asthma. Available from http://www.nhlbi.nih.gov/guidelines/ asthma/asthgdln.htm. Accessed 3 September 2008.

4. Regional Asthma Management and Prevention (RAMP). RAMP Asthma Action Plan. Available from http://www.rampasthma.org/AAP/AAPenglish.pdf. Accessed 17 February 2010.

5. Miller MR, Hankinson J, Brusasco F, et al. Standardisation of spirometry. Eur Respir J 2005;26:319-38.

6. Miller MR, Crapo R, Hankinson J, et al. General considerations for lung function testing. Eur Respir J 2005;26:153-61.

7. Vaswani R, Moy R, Vaswani SK. Evaluation of factors affecting peak expiratory flow in healthy adults: is it necessary to stand up? J Asthma 2005;42:793-4.

8. Nagasaki Y, Fujita E, Hazu R, Nishimura N, Nakajima S. A study on peak expiratory flow monitoring maneuver as compared to forced expiratory flow maneuver. Arerugi 1996;45:34-40. Japanese.

9. Harirah HM, Donia SE, Nasrallah FK, Saade GR, Belfort MA. Effect of gestational age and position on peak expiratory flow rate: a longitudinal study. Obstet Gynecol 2005;105:372-6. 